\title{
Adventures In Cyberspace: The Status Of Cybersquatting And ADR
}

Donavan Ropp, (E-mail: dropp@csub.edu), California State University, Bakersfield

Brian McNamara, (E-mail: bmcnamara@csub.edu), California State University, Bakersfield

\begin{abstract}
The University of Nowhere owns a trademark for the "University of Nowhere" and for the University of Nowhere "Winners," the university's sports teams. It also owns the domain name "www.un.edu." The University uses its Internet site to inform the public about its academic programs as well as its accomplishments on the sports fields. The University has been recognized as one of the top universities in the United States for many years. The University has also competed successfully for numerous NCAA titles over the years. The University discovers that Mr. First, owner of Fast Services of America, Inc., registered and is using the Internet domain name "university of nowhere.com" and "universityofnowherewinners.com" on a continuing basis. The University contacts Mr. First, who informs the University that he has no intention of relinquishing the domain names unless the University pays him \$10,000 and gives him two lifetime passes to all "Winner" games. The University declines the offer and writes a letter to Mr. First informing him that he must stop using the University domain names immediately. Mr. First responds by sending the University an invoice for \$10,000 and two lifetime tickets to "Winner" events. The cover letter to the invoice states that he will not stop using the domain names until the invoice is paid. This is now a dispute. It is going to cost money for both parties, regardless of the outcome. Additionally, there is the new area of law to contend with that relates to alleged cybersquatting and the improper use of domain names. This paper will explore and review approaches for resolving this dispute through negotiation, mediation, and arbitration.
\end{abstract}

\section{Introduction}

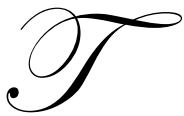

he cybersquatting example is a dispute situation that is most readily resolved, at least conceptually, by trademark law. With this in mind the following discussion will tackle how Alternative Dispute Resolution can be used to facilitate a resolution to the dispute.

\section{Alternative Dispute Resolution}

Alternative Dispute Resolution (ADR) is essentially a group or system of alternatives to litigation, short of self-help, or resolving disputes other than through traditional judicial processes. During the past 20 years, or so, ADR has developed into a legitimate substitute in resolving disputes. The fact is that in business transactions, it is neither feasible nor practical to litigate every dispute that arises. Litigation is costly, timely, very emotional, and may be a showstopper to a potentially profitable business transaction. Generally, business relationships are irreparably damaged through litigation. ADR, on the other hand, is less time intensive, less expensive, and usually results in continuing business relationships between and among the parties. In reality, only 5 to 10 percent of lawsuits filed go to trial. Many of these cases are finalized through a negotiated settlement, which de facto indicates the potential power of ADR.

Actually, ADR is alive and well in the United States and continues to develop as an effective tool within the business community in resolving disputes and consummating deals. One such area on the fast track

Readers with comments or questions are encouraged to contact the authors via email. 
is ADR processes that address issues relating to assigning domain names and cybersquatting on the Internet. This area of dispute resolution has a short but rich, productive, and successful history. [1] The dynamic start was finalized with the U.S. Department of Commerce signing a contract with the Internet Corporation for Assigned Names and Numbers (ICANN). The outcome will be discussed below under "Mediation" and "Arbitration." Moreover, discussions below will concentrate on negotiation, arbitration, and mediation for resolving disputes relating to domain name cybersquatting.

Negotiation: The simplest form of ADR is informal negotiations between and among the disputants in trying to reach a settlement or resolution to the issues of the dispute. This level of ADR is imperative to the process regardless of its likelihood of success or failure. Whatever the outcome of the negotiation and whether it takes 10 minutes or 10 hours, the time is well spent. First, the parties may come to unexpected conclusions that are beneficial to the interests of each and allow them to get on with the business at hand (the win-win approach). Or if no conclusion is reached, at least there may be better understanding as to the parties' positions, expectations, conditions, biases, misconceptions, etc. It may also help in providing additional information as to perceived bad faith and other emotional factors. The point is, even with no conclusion, the disputants are better prepared for the next level of ADR in resolving the alleged domain name-cybersquatting issues. That next step is either mediation or arbitration.

Mediation: Mediation is an ADR process where a third party, called a mediator, assists disputing parties in resolving their differences. A mediator is essentially powerless, in that $\mathrm{s} / \mathrm{he}$ cannot impose a binding solution on the parties. The plus side is that this third party neutral is often able to help the parties come to an understanding of the dispute and avoid future arbitration or litigation. The Internet Corporation for Assigned Names and Numbers (ICANN), to be defined in more detail below under "Arbitration," offers mediation services in alleged cybersquatting disputes. ICANN has established extensive mediation guides, procedures, rules, schedule of fees, and even suggested contract clauses and submission agreements.

Mediation followed by Arbitration (Med-Arb): The Internet Corporation for Assigned Names and Numbers (ICANN) also offers mediation followed, in the absence of a settlement, by arbitration. This procedure combines, sequentially, both mediation and arbitration. Where the parties agree to submit to the procedure, they must first endeavor to resolve the dispute through mediation. If a settlement is not reached through mediation within the period of time designated by the parties (either 60 or 90 days are recommended), the dispute may be referred by either party to arbitration for a binding decision. The down side is that either party may force a binding decision through arbitration with no right of appeal if the mediation does not resolve the disputed issues within the given time frame.

Arbitration: The Internet Corporation for Assigned Names and Numbers (ICANN) is responsible for regulating the issuance of domain names on the Internet. Since domain names are sometimes challenged for infringing on trademarks (names) owned by businesses and individuals, on October 1999, ICANN approved an arbitration procedure for challenging cybersquatting. This procedure is referred to as the Uniform Dispute Resolution Policy (UDRP). It requires arbitration of domain name disputes. Arbitration panels approved by ICANN hear disputes. UDRP panels are composed of experts in trademark and intellectual property and are usually retired judges, scholars, and other professionals. Per the above UDRP policy, all arbitrations procedures are conducted interactively via the Internet. The arbitration panel may rule for the complainant, the respondent, and, under certain conditions, have power to actually transfer registered domain names. Additionally, the panel may award damages against the respondent. Decisions of the arbitration panel may be appealed to the courts. Once an appeal is submitted to a court, the arbitration ruling is suspended.

Authorized arbitrator organizations include: the World Intellectual Property Organization (WIPO), an agency of the United Nations; the National Arbitration Forum (NAF); eResolution Consortium (eRes); and the CPR Institute for Dispute Resolution (CPR). All four of the dispute resolution providers follow ADR principles in dispute resolution. WIPO has processed the majority of cases under the ICANN dispute process.

The principles of the UDRP arbitration process almost parallel to the traditional legal remedies alluded to above. The person or business contesting the registration of a domain name must state that: (i) the domain name is 
identical or confusingly similar to a trademark (name) that the complainant has rights to; (ii) the registrant has no rights or legitimate interests in respect of the domain name; and (iii) the domain has been registered and is being used in bad faith. The procedure suggests four factors in establishing bad faith, including disrupting the claimants business or attempting, for personal gain, to bring forth confusion in the market place. The UDRP also includes three provisions for defenses by the registrant, including: (i) domain use in connection with a bona fide offering of goods and services; (ii) registrant has been commonly known by the domain name; and (iii) the registrant is making a legitimate noncommercial or fair use of the domain name, without intent of commercial gain or to confuse consumers or to tarnish the trademark (name) at issue.

\section{Application to the Abstract Case}

All indications from the Abstract above is that it appears that Mr. North is not interested in continuing a negotiation dialog with the University, and it's clear that the University has no intent of further negotiations with Mr. Fast. Negotiations broke down in the beginning of the dispute. A successful negotiation appears to be impossible at this time. Mediation and the use of a third party neutral to help in building consensus that will satisfy both parties is probably impossible at this time. Both sides are firmly dedicated to their position and there will probably be little movement, if any.

The most practical approach is to decide between legal remedies and arbitration. The rules relating to resolving alleged cybersquatting disputes are similar. The major difference is that legal remedies are more time consuming and cost consuming and are formal proceeding in a court of law. On the other side, the arbitration is required to be through the Internet Corporation for Assigned Names and Numbers (ICANN) and its arbitration agent, the World Intellectual Property Organization (WIPO), an agency of the United Nations that will use the Uniform Dispute Resolution Policy (UDRP) as described above. Additionally, the arbitration process will interact with the arbitration panel and the disputing parties via Internet. The Internet arbitration approach would save both parties time and money. When it all comes out in the wash it appears that arbitration is the route to go.

The arbitration panel would probably determine that University had a common law and trademark rights in University of Nowhere Winners, and that the domain names issues to Mr. Fast, the respondent, were confusingly similar to the University's trademark. Additionally, the panel would rule that Mr. Fast had no rights or legitimate interests in the domain name, and that they were registered and used in bad faith. Additionally, the respondent would have no legitimate interests in respect of the domain name where he had not used or developed the domain name for legitimate noncommercial or fair purposes or fair purposes and was not using the domain name in connection with a bone fide offering of goods or services. Lastly, the respondent, Mr. Lake, directly implied that he wanted a sum far greater than registration costs in exchange for the transfer of the two domain names. This action is a per se finding of bad faith. Final outcome: the University wins. What the University wins will depend on the documentation that the University originally filed. There could be deletion or transfer of the domain name and deletion of the domain name. Theoretically, the case would reach a similar conclusion in a traditional court ruling as discussed above under Traditional Legal Remedies.

\section{Conclusion}

What an incredible ending to a fast developing story. In keeping pace with changing technology and problems created by Internet domain name registration, a strange thing happened on the way to the forum. Current traditional legal principles parallel Alternative Dispute Resolution rules and procedures developed by the Internet Corporation for Assigned Names and Numbers (ICANN) for arbitration of Internet domain name-cybersquatting issues. The prima facie evidence requirements of one is compatible with the prima facie requirements of the other. This duel base lining has contributed greatly in streamlining the process of bringing some order to the cybersquatting issue.

The explosive growth and popularity of the Internet has proven challenging to the traditional business model. Complexities, complications, and expanding issues and categories will continue to expand as the Internet and the World Wide Web evolves. Areas of future Internet issues, that are already developing, include controversies over 
typo domains, hiding contact details, grudge sites (www.walmartsucks.com and www.aolsucks.com), generic domain names, geographic names, contracting, proper jurisdictions, and the list goes on. The merits of these issues will be discussed in future papers.

\section{Notes:}

1. Protecting your "SportsEvents.com:" Athletic Organizations and the Uniform Domain Name Dispute Resolution Policy; The West Virginia Journal of Law \& Technology, Vol. 5, No. 2, April 16, 2001.

\section{References:}

1. Baumer, David \& J.C. Poindexter (2002). Cyberlaw and E-Commerce, McGraw-Hill Irwin

2. Cabell, Diane. Using ICANN's Uniform Domain-Name-Dispute Resolution Policy (UDRP), The Berkman Center for Internet \& Society, April 2000

3. Chandrani, Rupesh. Cybersquatting - A New Right to Protect Individual Names in Cyberspace? Entertainment Law Review, Vol. 8, 2000

4. Davis, Benjamin G. The New Thing, Uniform Domain-Name Dispute-Resolution Policy of the Irnet Corporation for Assigned Names and Numbers, The Journal of World Intellectual Property, Vol. 3, No. 4, July 2000

5. D'Souza, Dinesh (2000). The Virtue of Prosperity. Finding values in an age of Techno-Affluence, The Free Press.

6. Girasa, Roy J. (2002). Cyberlaw: National and International Perspectives, Prentice Hall

7. Justice, Tom \& D.W. Jamieson (1999). The Facilitator's Field book, American Management Association.

8. Kane, Sam (1996). Facilitator's Guide to Participatory Decision-Making, New Society Publishers.

9. Martin, Chuck (1999). Net Future, McGraw-Hill. 